\title{
Consumption of Energy and Routing Protocols in Wireless Sensor Network
}

\author{
Ridha Azizi \\ Computer Technology Department, \\ High Institute of Technological Studies of Sousse (ISET), \\ Sousse, Tunisia $\quad$ BP 135 Cité Riadh ,Sousse Tunisia 4023 \\ Tel. (216) 98202807 \\ Email: azizi_ridha@yahoo.fr
}

Received: October 11, 2016 Accepted: November 28, 2016 Published: November 30, 2016

DOI: 10.5296/npa.v8i3.10257

URL: http://dx.doi.org/10.5296/npa.v8i3.10257

\begin{abstract}
Extend the life of a wireless sensor network (WSN) is a fundamental challenge, as they have a limited supply. Multiple protocols and approaches have been proposed to minimize power consumption. Routing protocols and especially the hierarchical approach is one of the techniques used to minimize energy consumption and to improve the duration of network life. In this paper we propose a new approach to transfer and select the $\mathrm{CH}$ (Cluster Head). ART-LEACH (Advanced Routing Transfer- Low-Energy Adaptive Clustering Hierarchy) is a self-organizing protocol based on clustering. Our approach is to use energy more evenly the selected nodes as $\mathrm{CH}$. We evaluated the performance of LEACH (Low-Energy Adaptive Clustering Hierarchy) and IB-LEACH (Improved and Balanced Low Energy Adaptive Clustering Hierarchy) protocol with the proposed new approach using MATLAB as a simulation tool. The simulation results showed that our proposal provides a reduction in energy consumption and increase the duration of network life.
\end{abstract}

Keywords : wireless sensor networks, routing protocol; clustering techniques LEACH; IB-LEACH; energy optimization. 


\section{Introduction}

Wireless sensor networks (WSN) consist of a set of very small devices, called sensor nodes, ranging from tens of elements to several thousand. In this type of network, each node is able to react in case of need by sending the information collected in one or more collection points, using a wireless connection.[1] [2] [3]. The sensor is provided with an energy source to power its components. However, due to its small size, energy resources at its disposal is limited and generally irreplaceable. To prolong the life of the network, several routing approaches have been proposed.

In this article we study the different routing protocols and existing improvements in a first section. In Section 2 we present a comparative study of different protocols. In Section 3, we present the existing improvements. In Section 4 we will detail the proposed improvement and results. Finally, Section 5 ends with a conclusion.

\section{Routing Protocols in Wireless Sensor Networks}

Routing protocols are actually split into three families: the routing protocols given central, hierarchical or geographical. In what follows, we cite a set of hierarchical routing protocols most widespread in applications of wireless sensor networks. It gives a brief overview on the principle of each:

\subsection{TEEN: Threshold-sensitive Energy Efficient sensor Network protocol:}

The network architecture is based on a hierarchical grouping several levels where the nearest nodes form clusters. Then this clustering process proceeds to the second level until the base station is reached [4,11].

\subsection{APTEEN: Adaptive Threshold-sensitive Energy Efficient sensor Network protocol}

It is a hybrid protocol that changes the frequency and threshold values used in TEEN according to user needs and the type of application [5].

\subsection{HEED: Hybrid, Eenergy-Efficient, Distributed approach}

HEED selects the cluster-heads in a hybrid test involving the remaining energy of the nodes and a second parameter such as the degree of the nodes. It aims to achieve a uniform distribution of cluster-heads in the network and to generate clusters balanced in size [6].

\subsection{LEACH protocol: Low-Energy Adaptive Clustering Hierarchy}

Form clusters to minimize power dissipation [7]

2.5 IB- LEACH protocol: Improved and Balanced Low Energy Adaptive Clustering Hierarchy

Uses gateways to reduce the cluster-head of energy consumption [8]. 


\section{Comparison of hierarchical routing protocols}

\subsection{The comparison criteria}

- Efficiency: Balance the load between the nodes of the network, improves the energy efficiency of sensor nodes, extend the life of networks and improve communication efficiency, which increases the period of stability and duration of network life. [8,3]

- Scalability: Scalability is an important factor in wireless sensor networks. A network zone is not always static, it changes according to the needs of users. All nodes in the area of network must be scalable and be able to adapt to changes in the structure of the network depending on the user. [9,2]

- The stability of clusters: The effectiveness of a clustering algorithm is evaluated in terms of the number of clusters formed and stability of the clusters according to the node mobility. The clustering process is mainly to optimize the maintenance information of the network topology and reduce the overhead of broadcasting for the discovery of paths. $[10,11]$

- Load Balancing: the main function of a WSN is to collect relevant information from an area of interest. Some applications, such as environmental control, need the WSN works as long as possible. Thus, the extension of the life of the WSN is important objective of each routing protocol. A poor load balancing will result in the rapid depletion of energy of some sensor nodes, as a result of a short lifetime of the WSN. A good routing protocol should ensure energy balancing to prolong the lifetime of WSN. [12]

\subsection{The comparative table}

Table 1 shows the classification of proposed protocols for WSNs, according to four criteria has been described previously (Energy efficiency, scalability, stability clusters, load balancing) [13,14].

Table 1 : Comparison of different hierarchical routing protocols in WSNs

\begin{tabular}{|c|c|c|c|c|}
\hline Protocols & Energy Efficiency & Stability clusters & Load Balancing & scalability \\
\hline TEEN & high & high & acceptable & low \\
\hline APTEEN & Moderate & Low & Very Low & Moderate \\
\hline HEED & moderate & moderate & high & low \\
\hline LEACH & High & moderate & moderate & strong \\
\hline IB-LEACH & High & moderate & moderate & Strong \\
\hline
\end{tabular}

\subsection{Advantages and disadvantages}

Table 2 shows the advantages and disadvantages of routing protocols in WSNs. 
Table 2 : Advantages and Disadvantages of routing protocols in WSNs

\begin{tabular}{|c|c|c|}
\hline Protocols & Advantages & Disadvantages \\
\hline $\mathrm{N}$ & $\begin{array}{l}\text {-Energy consumption in this protocol is } \\
\text { lower than in proactive protocols or } \\
\text { those that transmit data } \\
\text { periodically[15,1] }\end{array}$ & $\begin{array}{l}\text {-If the thresholds HT and ST are not received, the nodes will } \\
\text { never communicate, and no data will be transmitted to the } \\
\text { user and the base station does not know which nodes have } \\
\text { exhausted their energy } \\
\text { - TEEN is not suitable for applications that require periodic } \\
\text { mailings data }\end{array}$ \\
\hline APTEEN & $\begin{array}{l}\text {-Provides flexibility that allows the user } \\
\text { to select the CT time interval, and } \\
\text { threshold values HT and ST so that the } \\
\text { power consumption is controlled by the } \\
\text { variation of these parameters }\end{array}$ & $\begin{array}{l}\text { - Requires additional complexity to implement functions of } \\
\text { thresholds and time periods CT. } \\
\text {-The additional cost and complexity associated with the } \\
\text { formation of clusters at several levels are quite high [16] }\end{array}$ \\
\hline HEED & $\begin{array}{l}\text { - Ensures that all sensors are part of a } \\
\text { single cluster, and the cluster heads are } \\
\text { well distributed } \\
\text { - Extends the life of the nodes within the } \\
\text { network } \\
\text { - Creates widespread clusters }\end{array}$ & $\begin{array}{l}\text { - The Total evaluation presents some difficulty, because of } \\
\text { the absence of any central control } \\
\text { - Does not specify a particular protocol to be used for } \\
\text { communication between cluster-heads and the base station } \\
\text { - Clustering topology does not achieve minimum energy } \\
\text { consumption in the intra-cluster communication } \\
\text {-The clusters generated are not balanced in size. }\end{array}$ \\
\hline LEACH & $\begin{array}{l}\text {-It Provides scalability in network by } \\
\text { limiting most communications } \\
\text { within the different clusters. } \\
\text {-The Cluster-heads aggregate or merge } \\
\text { the information gathered by sensor } \\
\text { nodes, which helps to limit the traffic } \\
\text { generated in the network. } \\
\text {-The Role of the distributive property of } \\
\text { CH between cluster members. }\end{array}$ & $\begin{array}{l}\text {-This Significantly based on CHs rather than members of the } \\
\text { cluster nodes to communicate with the base station. Thus, he } \\
\text { incurs robustness problems such as failure of CHs. } \\
\text {-The CHs farthest from the base station quickly die with } \\
\text { respect to those } \\
\text { are close to the station. } \\
\text {-We Can not be CH during a round if the random numbers } \\
\text { generated by all } \\
\text { network nodes are higher than the probability T (n). [17] }\end{array}$ \\
\hline IB-LEACH & $\begin{array}{l}\text { - Balanced energy dissipation } \\
\text { - Lifetime of network is extended } \\
\text { - More stable region that LEACH } \\
\text { - The use of the bridge and CH reduce } \\
\text { the phenomenon of the rapid death of } \\
\mathrm{CH} \text { caused by excessive energy } \\
\text { consumption }\end{array}$ & $\begin{array}{l}\text { - Random Location bridges does not ensure an efficient } \\
\text { energy balance. } \\
\text { - The sensor node sends its data at the same } \mathrm{CH} \text { if it is closer } \\
\text { to the base station or gateway. } \\
\text { - The choice of the bridge is based solely on energy without } \\
\text { counting the distance which affects energy consumption }\end{array}$ \\
\hline
\end{tabular}

The study and analysis of the major routing protocols for WSNs, allowed us to offer our own routing protocol based on the assumptions of IB-LEACH whose main objective is the extension of the lifespan the network and the effective management of energy consumption. 


\section{Macrothink}

\section{Improvements proposed}

\subsection{Network Architecture}

ART-LEACH (Advanced Routing Transfer- Low-Energy Adaptive Clustering Hierarchy) is our protocol is a self-organizing protocol based on clustering as shown in Figure 1, which is to partition the network into groups (clusters). The nodes send their data to the cluster-heads $(\mathrm{CH})$, which in turn send the data to the base station (BS) via the gateway level 1 and 2.

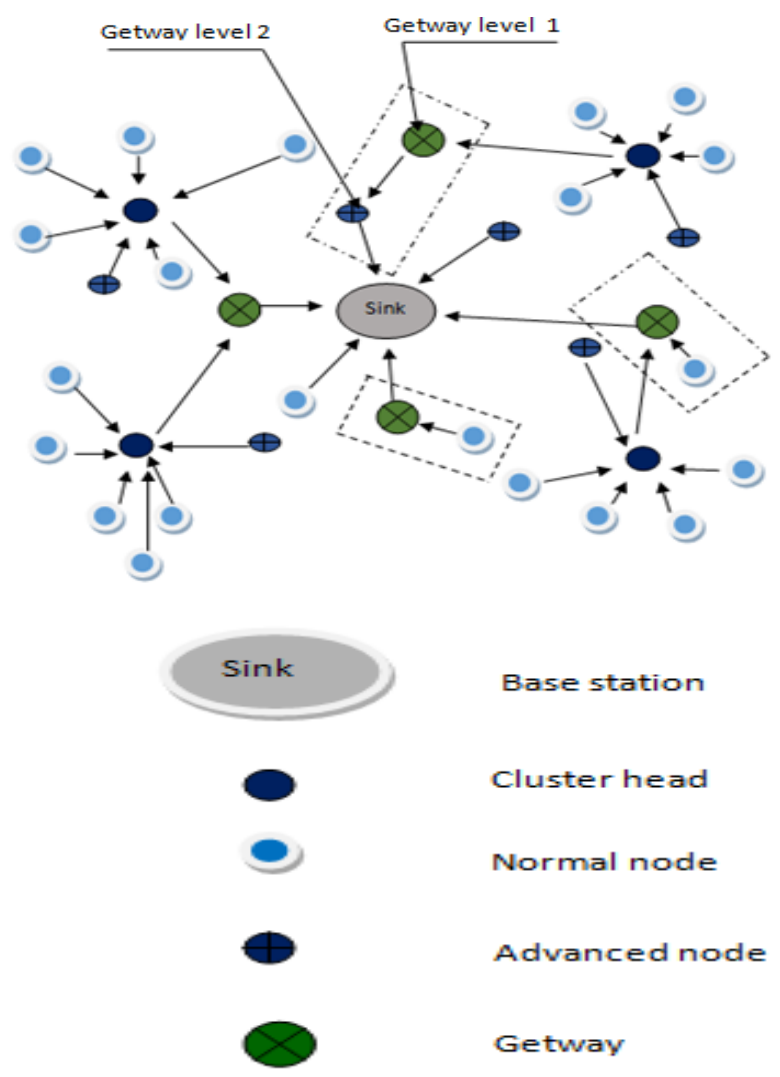

Figure1 : Network Model with ART-LEACH

The aim is to promote the nodes with more energy and close to the SB and belong to a well-defined zone (the zone gateways) to become level 1 gateways and seek advanced node that is located between the gateway level 1 and SB to become a level 2 gateway

\subsection{Election of gateways level 1}

Both parameters were combined (energy and distance) for calculating a threshold according to which the selected gateway level 1.

This threshold is calculated as follows:

$$
\text { threshold }=E / d
$$


Where $\mathbf{E}$ is energy current node and $\mathbf{d}$ is the distance between the node and the base station. The nodes having the highest threshold and belong to the gateway area choose to be gateways level 1.

\subsection{Election gateways Level 2}

To select gateways level 2 requires that the nodes are developed and located between the base station and the Gateway Level 1 as it is shown un Figure 2.

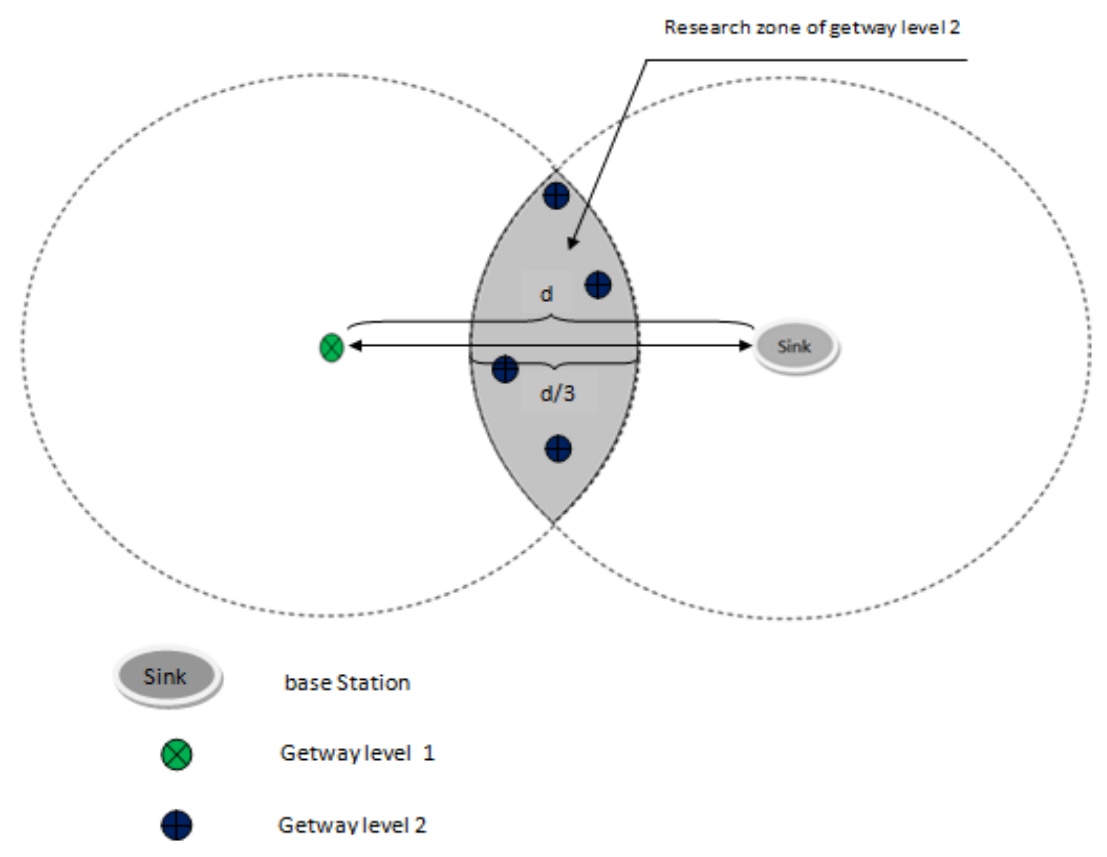

Figure 2: Zone gateways Level 2

Nodes having more energy are more likely to become second gateways. They send their ID and their energy to gateways level 1 and later it selects those with more energy to become gateways Level 2.

\subsection{ART-LEACH protocol operation}

The operation of ART-LEACH protocol is as follows:

The sensor nodes elect themselves to be gateways level 1 at one time with a certain probability. The base station confirms that if these nodes are suitable for bridges. As against the last take responsibility to elute the gateways level 2 with some restraint. The non-gateway nodes elect themselves for $\mathrm{CH}$ with a certain probability. Each node that will be designated $\mathrm{CH}$ or gateway for the current turn broadcasts a greeting message (ADV) to the rest of the nodes surrounding it.

The other nodes must keep their receivers tuned to hear the messages broadcast by the $\mathrm{CHs}$ and gateways, and each of these nodes decide which group to join for the current round 


\section{IIMacrothink}

by choosing the cluster-head or gateway, which requires minimum communication energy and sends a REQ-JOIN message notifying him of his membership. If a sensor node is very close to the base station, they will be directly connected.

After all the sensors are positioned, each $\mathrm{CH}$ creates a schedule for the nodes of the cluster. This allows the radio components of each sound cluster node to be deactivated at any time, except for its transmission time, which reduces the energy dissipated in the individual sensors.

The operation of the base station is shown in Figure 3.
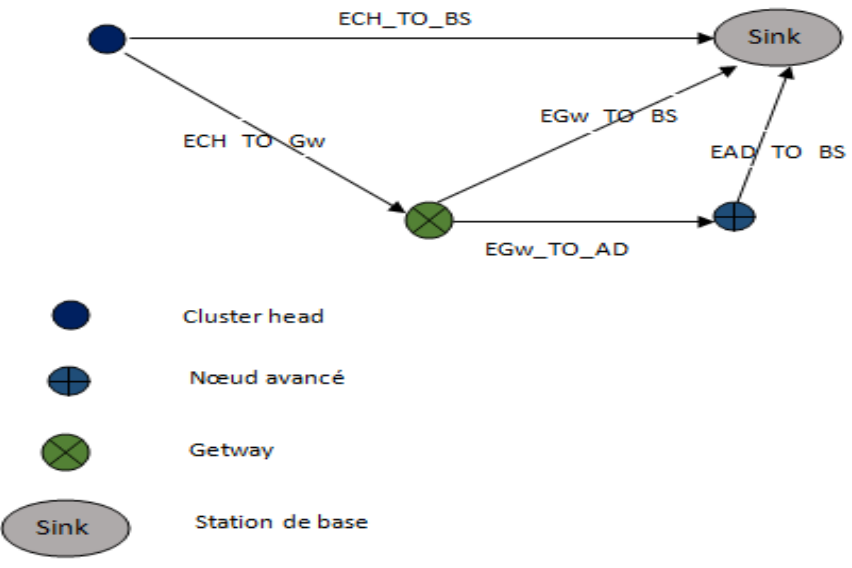

Figure 3 : Operation of the base station

Once the $\mathrm{CH}$ has all the data from their cluster members, it transmits them to:

- The base station if $\mathrm{ECH} \_\mathrm{TO} \_\mathrm{BS} \leq \mathrm{ECH} \_\mathrm{TO} \_\mathrm{Gw}+\mathrm{E} \mathrm{Gw}$ _TO_BS

$\mathrm{o} \mathrm{ECH} \_\mathrm{TO} \_\mathrm{BS}$ : the total energy dissipated to send the cluster-head data to the base station.

o $\mathrm{E}$ CH _ TO_ Gw: the total energy dissipated to send the cluster-head data to the gateway.

o E Gw _TO_BS: the total energy dissipated to send the gateway data to the base station.

o EGW _TO_AD: the total energy dissipated to send data gateway node to advanced (level gateway 2).

o EAD _TO_BS: the total energy dissipated node to send data to the advanced base station.

- The gateway level 1 if $\mathrm{ECH}$ _TO_BS > TO_Gw + E Gw _TO_BS

The gateway Level 1 subsequently transmits the data

- The base station if $\mathrm{EGW} \_\mathrm{TO} \_\mathrm{BS} \leq \mathrm{EGW} \_\mathrm{TO} \_\mathrm{AD}+\mathrm{EAD} \_\mathrm{TO}$ _BS

- The gateway level 2 if $\mathrm{EGW} \_\mathrm{TO} \_\mathrm{BS}>\mathrm{EGW} \_\mathrm{TO} \_\mathrm{AD}+\mathrm{EAD} \_\mathrm{TO}$ BS 
The individual sensors nodes send their data

- The gateway level 1 if EN_TO_Gw $<$ EN_TO BS and EN_TO_Gw < EN_TO_CH

- The base station if EN_TO BS < EN_TO_GW and EN_TO BS < EN_TO_CH

- The cluster-head if EN_TO_CH $<$ EN_TO_Gw and EN_TO_CH < EN_TO_BS

The operation of the gateway level 2 is shown in Figure 4.

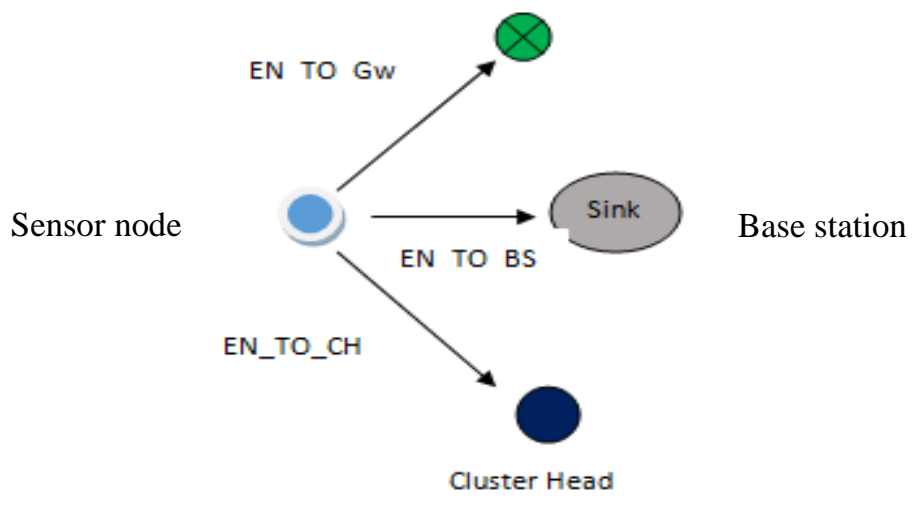

Figure 4 : Operation of gateway level 2

\section{Experimentation and results}

To evaluate the performance of ART-LEACH protocol was used MATLAB simulation, the parameters of our simulation are summarized in table 3 :

Table 3. Simulation parameters

\begin{tabular}{|c|c|c|}
\hline Settings & Definition & Value \\
\hline$(\mathrm{x}, \mathrm{y})$ & Location of the base station & $100,50)$ \\
\hline $\mathrm{N}$ & The number of nodes & $0.5 \mathrm{~J}$ \\
\hline E0 & initial Energy & $50.10-9 \mathrm{~J}$ \\
\hline E elec & Energy required to activate the electronic circuits & $5.10-9 \mathrm{~J}$ \\
\hline EDA & Energy required for data processing & $4000 \mathrm{bits}$ \\
\hline K & The packet size & $10.10-12 \mathrm{~J}$ \\
\hline Efs & free space model of the amplifier of the transmitter & $13.10-15 \mathrm{~J}$ \\
\hline Emp & Model multi-path of the amplifier of the transmitter & D0 $=\sqrt{ } \varepsilon f \mathrm{fs} / \mathrm{\varepsilon mp}$ \\
\hline D0 & Threshold distance & \\
\hline
\end{tabular}


Two parameters are chosen to evaluate the ART-LEACH protocol, which are the energy consumed and the number of dead nodes. In order to prove its effectiveness, we kept the same location nodes and conducted simulations of the three routing protocols LEACH, IB-LEACH and ART-LEACH.

\subsection{Evaluation of the energy consumed}

From the results of Table 4, we see that the protocol ART-LEACH consumes less power that the protocols LEACH and IB-LEACH. In LEACH CHs directly transmit the data packets to the base station and IB-LEACH they go through a gateway. The CHs that are far from the base station or gateway so will quickly deplete their energy reserves, which involves frequent reelections of $\mathrm{CHs}$ followed reconfigurations clusters. This results in a large consumption of energy of the entire network. ART-LEACH alleviates this problem with the presence of gateway level 2 which reduces the transmission distance from the leader nodes (last nodes) to the base station.

Table 4. Remaining power over time

\begin{tabular}{|c|c|c|c|c|c|c|c|c|}
\hline Tours & 1 & 200 & 400 & 600 & 800 & 1000 & 1200 & 1400 \\
\hline LEACH & 60 & 51.606 & 43.181 & 34.749 & 26.321 & 17.891 & 10.181 & 6.415 \\
\hline IB-LEACH & 60 & 52.121 & 44.09 & 35.983 & 27.826 & 19.589 & 11.862 & 8.6508 \\
\hline ART-LEACH & 60 & 52.037 & 44.43 & 37.297 & 30.521 & 24.126 & 18.225 & 13.04 \\
\hline
\end{tabular}

The improvement provided by ART-LEACH is further confirmed by the results in Figure 5. The latter shows the average power dissipation of all nodes by the three protocols over time. As it is clearly seen, ART-LEACH optimizes energy expenditure that LEACH and IB-LEACH.

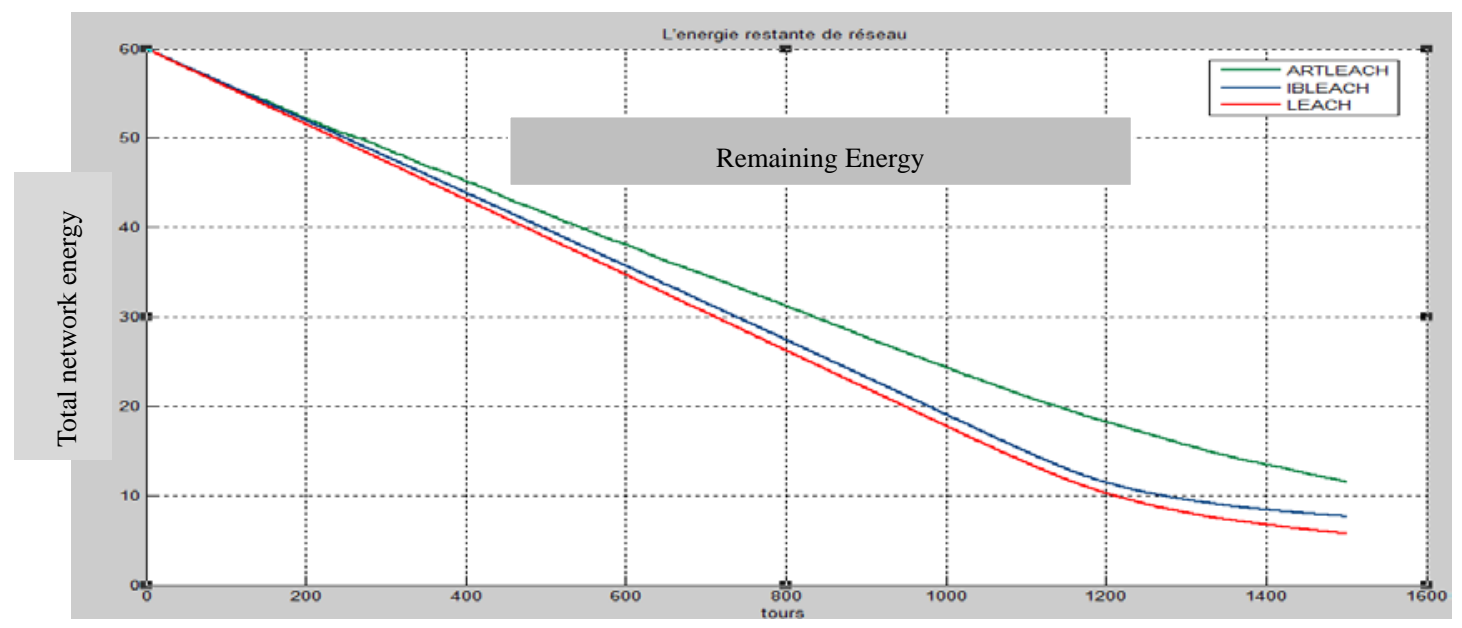

Figure 5 : Residual Energy vs rpm 


\subsection{Evaluation of number of dead nodes}

Table 5 summarizes the number of dead nodes obtained in each protocol as a function of the number of tours.

Table 5. Number of dead nodes /protocol

\begin{tabular}{|c|c|c|c|c|c|c|c|c|c|}
\hline Nours & 1 & $\mathbf{2 0 0}$ & $\mathbf{4 0 0}$ & $\mathbf{6 0 0}$ & $\mathbf{8 0 0}$ & $\mathbf{1 0 0 0}$ & $\mathbf{1 2 0 0}$ & $\mathbf{1 4 0 0}$ & $\mathbf{1 5 0 0}$ \\
\hline Nodes / Protocol & & & & & & & & & \\
\hline LEACH & 0 & 0 & 0 & 0 & 0 & 0 & 29 & 75 & 79 \\
\hline IB-LEACH & 0 & 0 & 0 & 0 & 0 & 0 & 27 & 77 & 79 \\
\hline ART-LEACH & 0 & 2 & 4 & 7 & 10 & 17 & 22 & 41 & 60 \\
\hline
\end{tabular}

In Figure 6, we compared the number of dead nodes in the three protocols. The first node of the protocol LEACH die after 1050 tours, like the IB-LEACH protocol, while the first node of the protocol ART-LEACH dies after 200 tours, but after 1200 tours it is clear that the number dead nodes in the protocols LEACH and IB-LEACH is higher than that of ART-LEACH which means the network operates as long as that is to say that we managed to extend the life network $40 \%$, this is an interesting result since in WSN all nodes must work together to accomplish a definite goal.

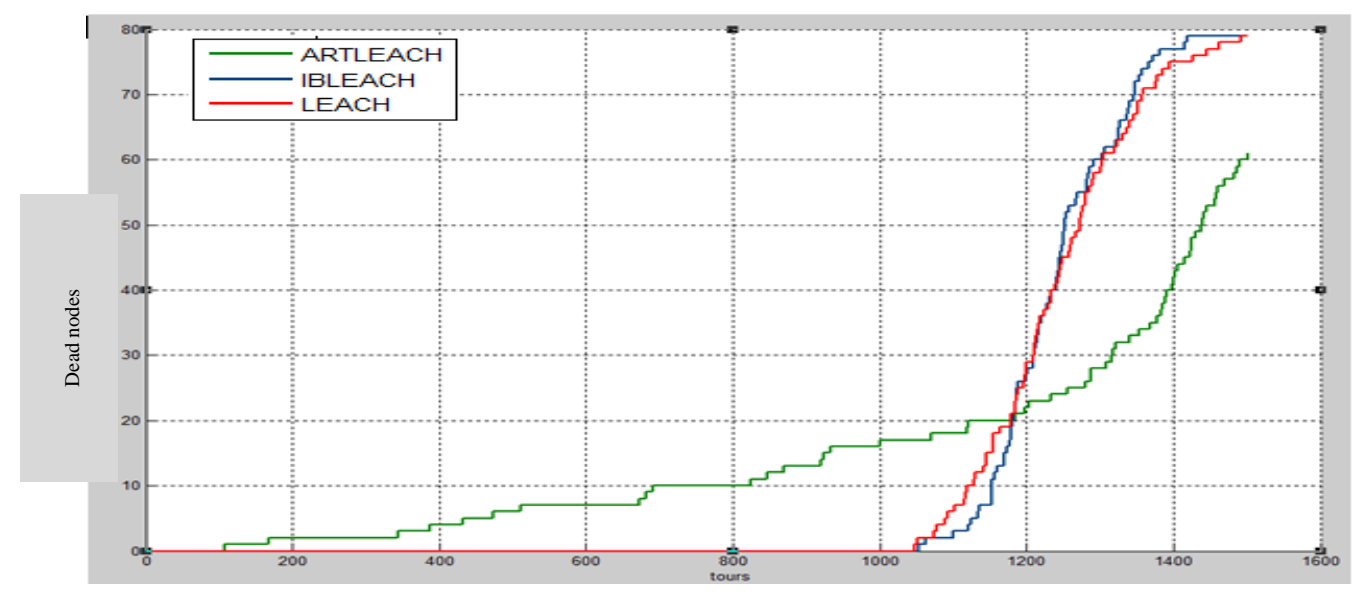

Figure 6 : Number of dead nodes vs number of tours

\section{Conclusion}

We studied the different routing protocols and respectful improvements proposed to extend the duration of life of WSN. In addition we proposed an improvement that takes into account nodes with maximum power and minimum distance from the base station belonging to a well-defined area (the bridge area) to become level gateways 1 and seek advanced node 
that is between the gateway level 1 and SB to become a gateway level 2. We conducted also experiments to assess in terms of the various improvements of the performance lifetime of the network. Based on simulation results, it was demonstrated that the ART-LEACH protocol improves power dissipation and increases the energy gain, as it extends the life of the network by $40 \%$ compared to LEACH protocol and IB-LEACH.

\section{References}

[1] Azizi. R. Comparative Study of Transport Protocols in WSN. International Journal of Computer Applications (0975 - 8887) Volume 113 - Issue 6. 2015. DOI : 10.5120/19827-1674

[2] Azizi. R. Comparative study of several MAC protocols proposed in WSN in Journal of Wireless Sensor Networks (JWSN ) Volume 2.2015.

[3] Azizi. R. Energy Consumption and Fault Tolerance in the MAC Protocols for WSN in Journal of Computer and Communications, (JCC) Volume 3, Number 6, 118-130.2015. DOI: 10.4236/jcc.2015.36012

[4] Amjad Mehmood , S. Khan , Bilal Shams , Jaime Lloret. Energy efficient multi level and distance aware clustering mechanism for WSNs, International Journal of Communication Systems, 2015, Vol. 28, No. 5, pp. 972-989.

[5] A. Manjeshwar, Arati and Agrawal, Dharma P. APTEEN: A Hybrid Protocol for Efficient Routing and Comprehensive Information Retrieval in Wireless Sensor Networks. IPDPS '02, 16th International Parallel and Distributed Processing Symposium. 2003.

[6] Denis Rosário, Rodrigo Costa, Helder Paraense, Kássio Machado, Eduardo Cerqueira, Torsten Braun, Zhongliang ZhaoA. Hierarchical Multi-hop Multimedia Routing Protocol for Wireless Multimedia Sensor Networks, Network Protocols and algorithms, 2012, Vol 4, No 4, pp. 44-64. DOI: http://dx.doi.org/10.5296/npa.v4i4.2121.

[7] S.Ben Alla, A. Ezzati and A. Mohsen « Hierarchical Adaptive Balanced Routing Protocol for Energy Efficiency in Heterogeneous Wireless Sensor Networks »,2010. http://dx.doi.org/10.5772/47789.

[8] Alkesh barman, Umapathi G.R , A comparative study on advances in LEACH routing protocol for wireless sensors,IJARCCE, Vol.3,Issue 2,February. 2014.

[9] Kyung Tae Kim and Hee Yong Youn. An Energy-Efficient and Scalable Routing Protocol for Distributed Wireless Sensor Networks, Adhoc \& Sensor Wireless Networks, 2015, Volume 29, Number 1-4, p. 195-212

[10] M. Bani Yassein, A. Al-zou'bi, Y. Khamayseh, W. Mardini , Improvement on LEACH Protocol of Wireless Sensor Network (VLEACH), International Journal of Digital Content Technology and its Applications Volume 3, Number 2. 2009.

[11] Amjad Mehmood, Jaime Lloret, M. Noman and Houbing Song. Improvement of the 


\section{Macrothink}

Network Protocols and Algorithms

ISSN 1943-3581

2016, Vol. 8, No. 3

Wireless Sensor Network Lifetime using LEACH with Vice-Cluster Head. Adhoc \& Sensor Wireless Networks, (2015), Volume 28, Number 1-2, p. 1-17.

[12] Femi A. Aderohunmu1, Jeremiah D. Deng2., An Enhanced Stable Election Protocol (SEP) for Clustered Heterogeneous WSN, Number2009/07 ISSN1177-455X.2009.

[13] Ian F. Akyildiz, Weilian Su, Yogesh Sankaraubramaniam, and Erdal Cayirci: A Survey on sensor networks, IEEE Communications Magazine .2002.

[14] José A. Gutierrez, Marco Naeve, Ed Callaway,MoniqueBourgeois,Vinay Mitter, Bob Heile, IEEE 802.15.4: A Developing Standard for Low-Power Low-Cost Wireless Personal Area Networks, IEEE Network, pp. 12-19 .September/October 2001.

[15] Sarjoun S. Doumit, Dharma P. Agrawal: Self Organizing and Energy-Efficient Network of Sensors, IEEE, pp. 1-6 (2002).

[16] Abuhelaleh, Mohammed Elleithy, Khaled Mismar, Thabet, Modified LEACH - Energy Efficient Wireless Networks Communication, Novel Algorithms and Techniques in Telecommunications and Networking, DOI 10.1007/978-90-481-3662-9_20. 2010.

[17] Wan Norsyafizan W.Muhamad, Kaharudin Dimyati, Roslina Mohamad, Rosmalini Abd Kadir, Evaluation of Stable Cluster Head Election (SCHE) Routing Protocol for Wireless Sensor Networks, Proceedings of the International MultiConference of Engineers and Computer Scientists 2010 Vol II, IMECS. 2010.

\section{Copyright Disclaimer}

Copyright reserved by the author(s).

This article is an open-access article distributed under the terms and conditions of the Creative Commons Attribution license (http://creativecommons.org/licenses/by/3.0/). 